\title{
STATISTICAL INTERPRETATION AND OPTIMIZATION OF VALSARTAN FLOATING TABLETS USING BOX-BEHNKEN DESIGN
}

\author{
SANKHA BHATTACHARYA ${ }^{1}$ \\ 1Department of Pharmaceutical Engineering and Technology, Indian Institute of Technology (Banaras Hindu University), Varanasi \\ 221005, Uttar Pradesh India \\ Email: sbhattacharya.pf.phe18@itbhu.ac.in
}

Received: 26 Apr 2019, Revised and Accepted: 06 Jun 2019

\begin{abstract}
Objective: The main purpose of this study was to formulate and statistically evaluate $300 \mathrm{mg}$ floating tablets of valsartan.

Methods: Floating tablets of valsartan was prepared in 16 station rotary punching machine by considering $300 \mathrm{mg}$ of valsartan as drug, $40-60 \mathrm{mg}$ of hydroxypropyl methylcellulose (HPMC) K100M and 20-40 mg of poly (styrene-divinylbenzene) as polymers and $20 \mathrm{mg}$ of sodium bicarbonate as gas generating agents. Since upper stomach has maximum therapeutic window for valsartan absorption, hence Gastroretentive Floating Tablets (GRFTs) was prepared by implementing Box-Bentham Design. The pre and post compression parameters were optimized using Statistica 10 software. From the in vitro buoyancy and drug release studies and interpretation of statistical outcomes viz. Akaike Information Criterion (AIC), Bayesian Information Criterion (BIC), Root Mean Squared Error (RMSE), Dissolution Efficiency (DE), Mean Dissolution Time (MDT), desirability study, it was concluded that batch VF5 formulation was found to be the most optimized formulation.
\end{abstract}

Results: The floating time of VF5 was found to be $132 \pm 0.33 \mathrm{sec}$, in vitro buoyancy time was $18 \mathrm{~h}$, Akaike Information Criterion (AIC) was 54.97 , Bayesian Information Criterion (BIC) was 5.13, percentage dissolution efficacy was 56.39\%, mean dissolution time was 5.19hr. Further, six-month stability study was performed as per ICH QIA guideline. After performing two-way ANOVA within stability study response variables, it was confirmed that the interaction was most significant.

Conclusion: Valsartan floating drug delivery system was successfully developed by considering HPMC K100M and poly (styrene-divinylbenzene) as polymers. Among all the nine batches, VF5 was found to be the best-optimized batch.

Keywords: Valsartan, Floating drug delivery system, Box-Bentham design, Akaike Information Criterion (AIC), Mean dissolution time (C) 2019 The Authors. Published by Innovare Academic Sciences Pvt Ltd. This is an open access article under the CC BY license (http://creativecommons.org/licenses/by/4.0/) DOI: http://dx.doi.org/10.22159/ijap.2019v11i5.33772

\section{INTRODUCTION}

Valsartan is basically an angiotensin II receptor antagonist. It has partial affinity for type I angiotensin receptor. Valsartan helps to reduce the blood pressure by blocking the action of angiotensin, which tenses to dilate blood vessels. It has versatile use in the treatment of Congestive Heart Failure (CHF), Post-Myocardial Infraction (MI). Eventually, valsartan blocks the binding of angiotensin II to the ATI receptor in adrenal gland and vascular smooth muscle [1]. Valsartan also restrict aldosterone secreting effects of angiotensin II, which ultimately leads to vasoconstriction [2]. The Biopharmaceutics Classification System (BCS) class II drug valsartan, is a white to partially fine powder with a molecular weight of 435.5 Daltons. Valsartan is slightly soluble in water but has good solubility in methanol and ethanol. The dose of valsartan is $40 \mathrm{mg}, 80 \mathrm{mg}$, and $320 \mathrm{mg}$. The LogP value of valsartan is 5.8 with $7.5 \mathrm{hr}$ of plasma half-life during oral administration [3]. Valsartan has higher therapeutic window at upper stomach. To target the upper stomach, Gastro Retentive Drug Delivery System (GRDDS) is one of the best approaches for valsartan drug delivery [4]. Hence, valsartan floating drug delivery system was planned, considering hydroxypropyl methylcellulose (HPMC) K100M and poly (styrene-divinylbenzene) as polymer. Valsartan has only $3 \%$ oral bioavailability, which means improvement of its bioavailability by sustaining its duration of drug release could be a novel approach [5]. In floating drug delivery system, the formulation retains in upper stomach for prolong period of time as this system has lower density then the Gastrointestinal Tract (GIT) fluid [6]. But most importantly, statistical interpretation of evaluation variables and optimization using Box-Bentham design could make this research more reliable[5]. Therefore, the basic interest of this research was to establish a proper statistical model and based on that optimizing best formulation.

\section{MATERIALS AND METHODS}

The drug valsartan was purchased from Pro Lab Marketing Pvt. Ltd. New Delhi, HPMC K100M was purchased from Kalpana Polymers
Private Limited, Mumbai-India, poly (styrene-divinylbenzene) was purchased from Rishichem Distributors Private Limited, MumbaiIndia. Lactose, sodium citrate, dicalcium phosphate, magnesium stearate, talc was gifted from Balaji Chemicals Vapi, Gujarat, India. All the other chemicals are reagents used were of pharmaceutical and analytical grads. For better results double distilled water was used throughout the experiment.

\section{Drug excipient compatibility studies using FTIR and DSC}

The pure drug valsartan was mixed with various polymers like HPMC K100M and poly (styrene-divinylbenzene). Further, IR mixture of all the components was prepared by considering potassium bromide $(\mathrm{KBr})$; as an alkali halide which helps to form a sheet that is transparent in the infrared region during pellet formation [7]. The pellet was formed by applying 10 tons of pressure in hydraulic press. The prepared pellets were scanned at 400 to $4000 \mathrm{~cm}-1$ wavenumber range in Fourier-Transform Infrared Spectroscopy (FTIR) Model ALPHAT, Libindia Analytical Instrument. Same way possibilities of drug excipient compatibility were identified by Differential Scanning Calorimetry (DSC). The changes of melting endotherms or variations of corresponding enthalpy of reactions helps to identify possible drug excipient interactions. In this experiment, DSC thermographs of pure valsartan drug, a mixture of drug with HPMC K100M and poly (styrenedivinylbenzene) were recorded. Using aluminum cells, the samples were separately sealed and analysed using DSC-60 instrument (Shimadzu Corporation, Tokyo, Japan). During this experiment temperature range were set up to $50-200^{\circ} \mathrm{C}$. The experiment was carried out in a nitrogen atmosphere at a heating rate of $5^{\circ} \mathrm{C} /$ minute.

\section{Implementation of box-bentham design}

When the variables and results of experiment having non-linear relationship, then Box-Bentham design could be the best alternative. With this design, nonlinear quadric effect and interaction between two variables can be studied [8]. In this experiment, the joint influence of 
independent variables concentration of HPMC K100M $\left[\mathrm{X}_{1}\right]$ and poly (styrene-divinylbenzene) $\left[\mathrm{X}_{2}\right]$ on the dependent variables, i.e. \% Cumulative Drug Release (CDR) at $4^{\text {th }}$ hour $\left(\mathrm{Y}_{1}\right)$ and $\%$ CDR at $8^{\text {th }}$ hour $\left(\mathrm{Y}_{2}\right)$. In this design two factors were investigated each at three levels. The possible experimental trials were considered up to nine batches (table 12). The further polynomial equation was established. The full model polynomial equation was established for this design.

$$
Y=\beta_{0}+\beta_{1} X_{1}+\beta_{2} X_{2}+\beta_{12} X_{1} X_{2}+\beta_{11} X_{1}^{2}+\beta_{22} X_{2}^{2}+E \text {, }
$$

Where, $\beta_{0}$ is intercepted, which is constant. The $\beta_{1}$ and $\beta_{2}$ are coefficient of $X_{1}$ and $X_{2}, \beta_{12}$ is the coefficient of interaction between $X_{1}$ $X_{2}$. The response variables mean $Y_{1}$ and $Y_{2}$ are subjected to multiple linear regression analysis. A further amount of formulation variables was optimized [9].

\section{Preparation of valsartan floating matrix tablet}

At first, the required quantities of drug, polymer, and excipients were accurately weighed and passed through sieve number 80 for proper size separation [10]. Further, along with valsartan, principal polymer HPMC K100M and low-density copolymer poly (styrene-divinylbenzene) were mixed geometrically. The effervescent agent i.e. Sodium bicarbonate, glidant i. e talc and magnesium stearate were added further in the polymeric drug mixture. These powder mixtures were than bladed using 1L Laboratory Blender (Thomas Scientific) and sieved using \#40 mesh. This blend was compressed using $12 \mathrm{~mm}$ diameter flat punch. For punching purposes, 16 stations rotary punching machine (Pacific tool private limited) was utilized. For this operation, type B tooling tablet punch was functionalized with $133.6 \mathrm{~mm}$ punch length and $19 \mathrm{~mm}$ punch diameter. The die diameter was $30.15 \mathrm{~mm}$ and die height was $2.22 \mathrm{~mm}$. The operational tablets were in plane face with $16 \pm 1.25 \mathrm{~mm}$ tablet size. The hardness of the operational twenty tablets was found on an average between $4-7 \mathrm{~kg} / \mathrm{cm}^{2}$.

\section{Evaluation parameters for valsartan floating tablet}

\section{Precompression parameters}

\section{Bulk density (BD)}

Accurately $10 \mathrm{gm}$ of excipients containing valsartan mixtures were taken and passed through sieve number \#10 and transferred into $100 \mathrm{ml}$ polypropylene-based graduated cylinder (Karter Scientific 19H2). Without any further compaction, settle the powder within and read the total volume it occupied. Then calculate the apparent bulk density $\left(\mathrm{g} / \mathrm{cm}^{3}\right)$ using following formula:

$$
\text { Bulk density }=\frac{\text { Total weight of granules }}{\text { Bulk volume }}
$$

\section{Tapped density (TD)}

The powder mixture containing valsartan, which was in the $100 \mathrm{ml}$ graduated cylinder was further compact using $50 \mathrm{ml}$ capacities digital tapped density apparatus (DBK Instruments Jogeshwari East, Mumbai), which could provide flexible drops of $14 \pm 2 \mathrm{~mm}$ at a marginal rate of 300 drops per minute. Initially, the cylinder was tapped for 500 times and tapped volume was been measured $\left(\mathrm{V}_{1}\right)$. Further, more 750 times tapping were recorded. The tapped volume was considered as $V_{2}$. As per procedure if the difference between $V_{1}$ and $V_{2}$ is lesser then $\%$, then the final volume $\left(V_{2}\right)$ can be considered for final tapped volume. The calculative tapped density $\left(\mathrm{g} / \mathrm{cm}^{3}\right)$ was measured by following formula:

$$
\text { Tapped density }=\frac{\text { Weight of the granuls }}{\text { Final tapped volume }}
$$

\section{Hausner ratio}

This is basically a fractional number which helps to predict flowability of powders or granules. If the Hausner ratio of any granules or powders is more than 1.25 , which indicates poor flowability. Hausner Ratio can be represented by the following equation:

$$
\text { Hausner Ratio }=\frac{\text { Tapped Density }}{\text { Bulk Density }}
$$

\section{Carr's index}

The particular compressibility and cohesivity of granules can be measured by Carr's index or Carr's compressibility index. This is also an important parameter to measure the particle size of granules. If Carr's Index of any granules is between $5-15 \%$, indicates that the granules have excellent flowability.

$$
\text { Carr's Index }=\frac{\text { Tapped density-Bulk dennsity }}{\text { Tapped density }} \times 100
$$

\section{Angle of repose}

Using the funnel method, the angle of repose of powder was determined. The funnel was filed with accurately weighted granules. The height of the funnel was adjusted such a way that, the funnel tip can touch apex of the powder blend. The final bland of granules were allowed to flow through the funnel tip into the surface of graph paper. The diameter of powder cone was measured and angle repose was calculated using following formula.

$$
\theta=\tan ^{-1} \mathrm{~h} / \mathrm{r}
$$

\section{Total porosity}

At first total volume of granules occupied in $100 \mathrm{ml}$ cylinder was measured, then tapped volume was noted down after 100 tapping. The volume of the void was calculated as the difference between total volume of granules and tapped volume. The percentage porosity was calculated using the following formula:

Porosity $=($ Total Volume-Volume of the Solid $) /$ Total Volume $) \times 100 \%$.

\section{Drug content}

An accurately weight of $100 \mathrm{mg}$ of valsartan powder blend. This blend was further extracted with $0.1 \mathrm{~N} \mathrm{HCl}$ and the solution was filter through $0.45 \mu$ membrane. The absorbance was measured at 50 $\mathrm{nm}$ after suitable dilution using Shimadzu UV-1601PC UV-Visible, Scanning Spectrophotometer.

\section{Post compression parameters}

\section{Weight variation}

Randomly twenty tablets were selected during process of manufacturing and average weight was measured. The individual tablet weight was measured and compared with average weight of tablets. The weight variation of tablet was estimated and percentage deviation was reported. Weight variation of all the batches of formulations was determined and recorded.

$$
\text { Percentage deviation }=\frac{\text { Individual weight }- \text { Average weight }}{\text { Individual weight }}
$$

\section{Hardness}

The hardness of the tablet was determined by Vin Syst Manual Tablet Hardness Tester (Monsanto Type); Model Number: VMT-1. Randomly three tablets from each batch were selected and the average hardness with standard deviation was recorded.

\section{Friability}

Friability test for uncoated tablets is prerequisite to know the tendency of tablets to chip, crumble or break during shipping, handling or during storage. Friability test was performed by HMK Tablet 1601 friabilator. Where, rotation speed was maintained around $5 \pm 1$ revolution/minute, timings at 9:59:59 min. During drum rotation, ten pre-weighted tablets were subjected to fall within six inches of rotatory drum surface. After rotation cycle, tablets were dusted and once again weight was measured.

$$
\text { Friability }=\frac{\text { Ten tablets weight before frability }- \text { Ten tablets weight after friability }}{\text { Ten tablets weight before friability }} \times 100
$$

\section{Drug content}

At first, ten tablets were taken and the average weight was measured. Further, tablets were triturated to get fine powder. A certain quantity of powder equivalent to $80 \mathrm{mg}$ of valsartan was taken and admixed with $100 \mathrm{ml}$ of $0.1 \mathrm{~N} \mathrm{HCL}$. The solution was further filtered using cellulose acetate membrane filter $(0.30 \mu \mathrm{m})$. Further, $1 \mathrm{ml}$ of this solution was diluted with $100 \mathrm{ml}$ of $0.1 \mathrm{~N} \mathrm{HCL}$ and using Shimadzu UV-2600 spectrophotometer at $50 \mathrm{~nm}$ absorbance was taken to measure drug content. 


\section{In vitro buoyancy study}

The time at which tablet rises to the surface of dissolution medium is considered as floating time and the duration on which tablet floated on the dissolution medium was noted as floating lag time respectively. The test was performed at $37 \pm 0.5^{\circ} \mathrm{C}$ in $50 \mathrm{ml}$ beaker containing $00 \mathrm{ml}$ of $0.1 \mathrm{~N}$ HCL solution [11].

\section{In vitro drug release study}

Drug release study was attained by TDT-06P (Electrolab) USP type II dissolution testing apparatus. In this in vitro drug release study, $900 \mathrm{ml}$ of $0.1 \mathrm{~N}$ HCL were used as a dissolution media. The paddle RPM was set to 50 and the temperature was maintained around $37^{\circ} \mathrm{C} \pm 0.5^{\circ} \mathrm{C}$. During dissolution study at various time intervals, $5 \mathrm{ml}$ of dissolution media was withdrawn and filtered using $0.45 \mu$ membrane filter. Simultaneously fresh $5 \mathrm{ml}$ of $0.1 \mathrm{~N}$ HCL was added in dissolution media to maintain 900 $\mathrm{ml}$ of system volume. The samples were withdrawing for each one-hour interval and up to 8th hour samples were withdrawn. Freshly withdrawn samples were further diluted with 0.1N HCL and absorbance was taken at $50 \mathrm{~nm}$ using Shimadzu UV-1601PC UV-Visible, scanning spectrophotometer [12]. The amount of drug release was calculated using standard curve equation.

\section{Statistical analysis}

The statistical analysis of the variables is very essential to established good correlation between dependent and independent variables. The Box-Bentham design was established using Design Expert 11 (STATEEASE) and Minitab® 18 softwares. In this experiment, two factors that is \% CDR at $2^{\text {nd }}$ hour and \% CDR at $8^{\text {th }}$ hour have been evaluated, considering each at three levels $(-1,0,+1)$. Total nine batches of possible combinations were generated by Design of Expert 11 software. Further, two-way analysis of variance was established. With this statistical model various graphical representations were also established to analysis each factor with different level of responses. The various graphical representations like, FDS graphs, Residual vs Predicted, Residual vs Actual, Counterplot of $\%$ CDR at $2^{\text {nd }}$ and $8^{\text {th }}$ hour respectively, 3D surface plot of $\%$ CDR at $2^{\text {nd }}$ and 8 th hour respectively, desirability, overlay plot, pareto chart of the standard effects, individual value analysis, probability plot, overlay plots were helps to analysis statistical models completely.

\section{Checkpoint batch and optimization of formulations}

The checkpoint batch was mandatory to find correlation between the polynomial equations and counterplot while predicting the responses. Optimization of the variables was measured using significant coefficients and $\mathrm{R}^{2}$ value.

\section{Kinetic studies}

Drug release studies can be well defined by selecting suitable kinetic models like zero order kinetics, first-order kinetics, higuchi model, hixson crowell cube root model, korsmeyer peppas equation [13]. Nevertheless, Akaike Information Criterion (AIC) [14], Bayesian Information Criterion (BIC) or Schwarz Criterion (SC), K1, Root Mean Squared Error (RMSC), Dissolution Efficiency (DE), Mean Dissolution Time (MDT) estimation using KinetDS 3 rev 010 software, helps to estimate the best fit model and best formulation within nine formulations [15].

\section{Stability study}

Accelerated stability studies was performed as per ICH guideline at 40 ${ }^{\circ} \mathrm{C} \pm{ }^{\circ} \mathrm{C} / 75 \% \mathrm{RH} \pm 5 \% \mathrm{RH}$ for 6 mo. Accelerated stability study on optimized formulations helps us to find the effect of ingredients on physical and chemical stability of active pharmaceutical ingredient of the dosage form. Tablet was stored in an aluminum foil and formulation was exposed in elevated temperature and humid conductions as specified earlier. Samples were withdrawn in every mounts and various evaluation tests were performed [12].

\section{RESULTS AND DISCUSSION}

\section{IR and DSC results for valsartan and excipient compatibility}

It was observed that there was no chemical interaction between Valsartan and the polymers used. The functional group present in drug give peaks to specify the presence of 5-cyclic ring with oxygen atom, diamine and alkene, and other peaks for nitro groups. On the basis of DSC analysis, the valsartan melting point was found to be $102.12^{\circ} \mathrm{C}$; however the melting isotherm shafted to $198.56^{\circ} \mathrm{C}$ while combination with drug and polymers.

\section{Pre compression parameters and evaluations}

Each batch was planned for 50 tablets, hence $15 \mathrm{~g}$ bland was prepared. Bulk density was measured using Veego digital bulk density apparatus (Model number: VTAP/MATIC-II). Bland was placed in $100 \mathrm{ml}$ of polypropylene-based graduated cylinder (Karter Scientific 19H2) and bulk density was measured. Further using 100 tapping of cylinder, tapped density was recorded. The various precompression parameters were evaluated and were found to be within the prescribed limits. Using Statistica10 $₫$ software, the pre compression parameters were recorded and variable importance graph was plotted. It was observed that total percentage porosity (power value: 0.996230 ) has maximum influence on floating tablet manufacturing and angle of repose (power value: 0.535868 ) has less importance on tablet preparation. All these results indicate, all the batches blend has well to passable flow and micropolitics (table 34). In post-compression parameters at first, weight variations of tablets from the different batches was calculated and reported (table 5). Almost all the formulation passed the weight variation test as the percentage weight variation was within the pharmacopeia limits of $\pm 5 \%$ of the weight. The VF3 formulation possessed maximum average weight of $302.21 \mathrm{mg}$ with a weight variation of $\pm 0.514 \%$, and the VF2 batch has less average weight of $98.23 \mathrm{mg}$ with a weight variation of $\pm 0.809 \%$. Similarly, the average drug content of VF6 batch tablets was considered to be the highest i.e. $99.13 \%$, where else VF1 shows less drug content of $92.24 \%$. Further the hardness of all the batch samples was measured using tablet hardness tester (Monsanto Type); model number: VMT-1. The average hardness of VF8 batch was found to be maximum i.e. $6.4 \pm 0.27 \mathrm{~kg} / \mathrm{cm}^{2}$ and VF5 batch recorded lowest average hardness i.e. $4.8 \pm 0.51 \mathrm{~kg} / \mathrm{cm}^{2}$. The average thickness of all the tablets was recorded using vernier calliper, VF6 batch recorded $5.1 \pm 0.15 \mathrm{~mm}$ thickness; which was considered to be minimum among all the batches, where else VF7 recorded maximum thickness, which was recorded around $5.8 \pm 1.82$ $\mathrm{mm}$. As far as the percentage friability was concerned, friability was recorded using HMK Tablet 1601 friabilator, considering 10 tablets of one batch at a time in friabilator. All the batches were recorded within the limit of friability range, however VF5 recorded maximum friability of $0.613 \pm 0.22 \%$, where else VF1 shows lest friability of $0.412 \pm 0.28 \%$ among all the batches. The floating time was a prerequisite variable for this formulation design. Floating time of VF1 was recorded $116 \pm 0.37$ see which is lest among of all the batches, where else VF3 shows maximum floating time of around $136 \pm 0.02$ see. The formulation BF4, VF6 and VF9 shows maximum buoyancy where else VF1 shows minimum buoyancy within all the batches. Using Statistica $10 \AA$ software the post-compression parameters were recorded and variable importance graph was plotted. It was observed that average thickness (power value: 0.923526) has maximum influence on floating tablet manufacturing and (power value: 0.535868) has less importance on tablet preparation. All these results indicate, all the batches blend has well to passable flow and micropolitics properties (table 6).

\section{In-vito drug release study}

All the nine batches (VF1-VF9) of valsartan floating tablets were developed considering HPMCK100M (40-60 mg) and poly (styrenedivinylbenzene); $0-40 \mathrm{mg}$ as polymers. All the batches were subjected to in vitro drug release study using $0.1 \mathrm{~N}$ HCL for $12 \mathrm{~h}$. The cumulative drug release profile was mentioned (fig. 1). The result shows that, VF5 formulation has controlled and better drug release profile $\left(99.38 \pm 0.145\right.$ at $12^{\text {th }}$ hours of dissolution) with $50 \mathrm{mg}$ HPMCK100M and $30 \mathrm{mg}$ poly (styrene-divinylbenzene) polymer concentration. There for it can be considered as optimum batch, however, proper statistical analysis and kinetic analysis was warranted to come in a conclusion.

\section{Statistical analysis}

Box-Bentham design was implemented to identified best possible factors. Preliminary investigation revealed that factor concentration of 
poly (styrene-divinylbenzene) (20-40 mg)- $\mathrm{X}_{2}$ and HPMCK100M (40-60 $\mathrm{mg})-\mathrm{X}_{1}$ is highly influenced the in vitro drug dissolution profile.

\section{Effect of polymers concentration on $\% \mathrm{CDR}$ at $2^{\text {nd }} \mathrm{h}$}

Using Design Expert® 11 software in vitro percentage cumulative drug release study was statistically interpreted at $2^{\text {nd }}$ hour. Based on ANOVA analysis, quadric model was selected. In quadric model, Fvalue was 1201.78 , which implies the model was significant. There is only a $0.01 \%$ chance that an F-value this large could occur due to noise. Statistically, F value helps to indicate a group of variables are jointly significant or not. The $\mathrm{F}$ value of test is larger than $\mathrm{F}$ statistics, hence rejection of null hypothesis is palpable and accepting the alternative hypothesis was acceptable. Nevertheless, P-values less than 0.0500 indicate model terms were significant. In this case $X_{1} X_{2}$, $\mathrm{X}_{1} \mathrm{X}_{2}, \mathrm{X}_{2}{ }^{2}$ are significant model terms. Values greater than 0.1000 indicate the model terms were not significant. The Predicted Quadric $\mathrm{R}^{2}$ of 0.9944 is in reasonable agreement with the Adjusted $\mathrm{R}^{2}$ of 0.9987; i.e. the difference is less than 0.2 The Predicted $R^{2}$ of 0.9944 is in reasonable agreement with the Adjusted $R^{2}$ of 0.9987 ; i.e. the difference is less than 0.2. Precision measures the signal to noise ratio. A ratio greater than 4 is desirable. In this experiment adequate precision was 102.608 , indicates an adequate signal. This model can be used to navigate the design space.

\section{The polynomial equation for $\% \operatorname{CDR}$ at $2^{\text {nd }} \operatorname{Hour}\left(\mathrm{Y}_{1}\right)=+28.39$ -} 6.32 $\mathrm{X}_{1}-4.40 \mathrm{X}_{2} 3.04 \mathrm{X}_{1} \mathrm{X}_{2}+0.1100 \mathrm{X}_{1}{ }^{2}+0.6450 \mathrm{X}_{2}{ }^{2}$

The higher value of correlation coefficient for \% CDR at $2^{\text {nd }}$ hour signifies a good fit model. The coefficient of $\mathrm{X}_{1}$ and $\mathrm{X}_{2}$ was significantly lower and negative, indicating decrease in polymer concentration $\left[\mathrm{X}_{1}=\right.$ HPMCK100M (40-60 mg), X2=poly (styrene-divinylbenzene) (20-40 $\mathrm{mg})]$ could increase the percentage cumulative drug release at $2^{\text {nd }}$ hour. Where else, a combination of $\mathrm{X}_{1} \mathrm{X}_{2}$ and individual squares of $\mathrm{X}^{2}$ and $\mathrm{X}_{2}{ }_{2}$ has agonistic effect with drug release, means drug release could get decrease with increase concentration of $X_{1}$ and $X_{2}$. But the coefficient values of $\mathrm{X}_{21}, \mathrm{X}_{2}{ }_{2}$ and $\mathrm{X}_{1} \mathrm{X}_{2}$ was smaller, means has less influence on \% CDR at $2^{\text {nd }}$ Hour. (table 7 and 8).

From the counterplot, it was confirmed that HPMC K100M; $50 \mathrm{mg}$ and poly (styrene-divinylbenzene); $30 \mathrm{mg}$ concentration provides good drug release profile (Coded value: 0,0 ). That means VF5 formulation batch have proper dissolution profile. On the other hand, from 3D surface plot, it was assumed that decrease concentration of polymers could increase the percentage cumulative drug release in parallel manner. From the residual vs run model it was confirmed that except one, all the formulation retained between the limits of externally standard units. From predicted vs actual curve, it was confirmed that the statistical model maintained good linearity and design predicted \%CDR at $2^{\text {nd }}$ hour is almost coincide with actual \%CDR at $2^{\text {nd }}($ fig. 2 ).

\section{Effect of polymers concentration on \%CDR at 8th hour}

Using Design Expert ${ }^{\circledR} 11$ software in vitro percentage cumulative drug release study was statistically interpreted at $8^{\text {th }}$ hour. Based on ANOVA analysis, quadric model was selected. In the quadric model, F-value was 332.16 , which implies the model was significant. There was only a $0.03 \%$ chance that an F-value this large could occur due to noise. Statistically, F value helps to indicate a group of variables are jointly significant or not. The $F$ value of test is larger than $F$ statistics, hence rejection of null hypothesis is palpable and accepting the alternative hypothesis was accepted. Nevertheless, Pvalues less than 0.0500 indicate model terms were significant. In this case $\mathrm{X}_{1} \mathrm{X}_{2}, \mathrm{X}_{1} \mathrm{X}_{2}, \mathrm{X}_{2}{ }^{2}$ are significant model terms. Values greater than 0.1000 indicate the model terms were not significant.

The Predicted $\mathrm{R}^{2}$ of 0.9859 is in reasonable agreement with the Adjusted $\mathrm{R}^{2}$ of 0.9952 ; i.e. the difference is less than 0.2. Adequate Precision measures the signal to noise ratio. A ratio greater than 4 is desirable. In this experiment ratio was 57.338 indicates an adequate signal (table 9and10). This model can be used to navigate the design space.

\section{Polynomial equation for \% CDR at $8^{\text {th }}$ Hour $\left(\mathrm{Y}_{2}\right)=+84.05-4.58 \mathrm{X}_{1^{-}}$ $3.86 X_{2} 0.2400 X_{1} X_{2}+0.4150 X_{1}{ }^{2}+0.2100 X_{2}{ }^{2}$}

The moderate-higher value of correlation coefficient for $\%$ CDR at $8^{\text {th }}$ hour signifies a good fit model. The coefficient of $X_{1}$ and $X_{2}$ was significantly lower and negative, indicating decrease in polymer concentration $\left[\mathrm{X}_{1}=\right.$ HPMCK100M $(40-60 \mathrm{mg}), \mathrm{X}_{2}=$ divinylbenzene) (20-40 mg)] could increase the percentage cumulative drug release at $8^{\text {th }}$ hour. Where else, combination of $\mathrm{X}_{1} \mathrm{X}_{2}$ has shown negative sign with low coefficient value $(0.2400)$, indicating increase in drug release profile. The individual squares of $\mathrm{X}^{2}{ }_{1}$ and $\mathrm{X}_{2}{ }_{2}$ have agonistic effect with drug release, means drug release could get decrease with increase concentration of $X_{1}$ and $X_{2}$. But the coefficient values of $X^{2}{ }_{1}$, $\mathrm{X}^{2}{ }_{2}$ and $\mathrm{X}_{1} \mathrm{X}_{2}$ were smaller, means has less influence on $\%$ CDR at $8^{\text {th }}$ Hour. From the counterplot, it was confirmed that HPMC K100M; 50 $\mathrm{mg}$ and poly (styrene-divinylbenzene); $30 \mathrm{mg}$ concentration provides good drug release profile (Coded value: 0,0 ). that means VF5 formulation batch have proper dissolution profile after $8^{\text {th }}$ hour of dissolution. On the other hand, from 3D surface plot, it was assumed that decrease concentration of polymers could increase percentage cumulative drug release in parallel manner. From the residual vs run model it was confirmed that except one, all the formulation retained between the limits of externally standard units. From predicted vs actual curve, it was confirmed that the statistical model maintained good linearity and design predicted \%CDR at $8^{\text {th }}$ hour was almost coinciding with actual \%CDR at $8^{\text {th }}$ hour (fig. 3).

\section{Probability plot}

With probability plot one can easily predict whether response variables follow a normal distribution or not. The response variables should coincide with the theoretical distribution and form approximately a straight line. Probability plot also helps to provide highest correlation coefficient. In this experiment, \%CDR at $2^{\text {nd }}$ and $8^{\text {th }}$ hour's shows highest good correlations means drug releases with significance manner and maintain zero-order kinetics (fig. 4).

\section{Desirability function}

Desirability is a design function which ranged from zero to one. Among multiple function, numerically a point which is closer to one is more desirable. The overall desirability was found to be 0.927 . From the 3D and counter desirability plot, it was confirmed that maximum desirability obtained at HPMC K100M (50 mg) and Poly (styrene-divinylbenzene) (30 mg) concentration (Coded value: 0 , 0)(fig. 5).

\section{Checkpoint analysis and optimization of batch}

From the optimization parameters and desirability study, it was anticipating that VF5 batches formulations could be the optimized one. To understand properly three checkpoint batches (VF10, VF11, and VF12) was prepared. The $2^{\text {nd }}$ and $8^{\text {th }}$ hours of \%CDR was compared with predicted values of the overly plot. In overlay plot, yellow colour space indicates maximum possibility to produce desired formulation within this lining. The relative standard error must not exist 9\%. This is very crucial part of Response Surface Methodology (RSM); as after studying the effect of independent variables on dependent variables or response variables, the optimum response was determined. It was observed that response variables of checkpoint batches were cognitive with VF5 formulations (table 11), hence VF5 batch can be considered as optimized batch. However, drug kinetic study is needed to select best formulation with good controlled release property.

\section{Kinetic studies}

The kinetic study of drug dissolution profiles of all the formulations was prerequisite to find best-optimized formulation. However, from the Design Expert output, VF5 was selected as the best batch. But, without kinetic study one cannot predict the actual reality of drug release pattern. In this study, the drug release profile with time was fitted with various models. The criteria for selecting best fitting model were, the regression coefficient $\left(\mathrm{R}^{2}\right)$, which must be near to one. Similarly, AIC, BIC, K1, RMSE, Dissolution Efficiency (DE) must be in lest number in best selected model as compare to other models. As far as Mean Dissolution Time (MDT) was concerned, which indicates 50\% of drug release from the formulation, can helps to characterize the retarding rate of polymers and drug-releasing ability. A higher MDT value indicates a higher drug retarding ability of polymers. The formulation VF5 has shown highest MTD value (5.19) as compare to other formulations, indicating $50 \mathrm{mg}$ of HPMC K100M and $30 \mathrm{mg}$ of 
poly (styrene-divinylbenzene) has good drug retarding ability, where else VF2 with $50 \mathrm{mg}$ HPMC K100M and $0 \mathrm{mg}$ poly (styrenedivinylbenzene) shows lest MDT value of 3.431, indicating poor polymeric retention of drug with higher drug release. The Percentage Dissolution Efficacy (DE) was also found to be moderately high (56.39\%). Similarly, Bayesian Information Criterion (BIC) or Schwarz Criterion and Akaike information criterion (AIC) also helps to find best model among finest set of models; the model with the lowest BIC and AIC values was preferred as best model. AIC helps to find best quality and goodness of fit model. Within all formulations once again, VF5 has lowest AIC (54.97) and BIC (55.13) value. On the contrary, VF5 follow zero-order kinetics as $\mathrm{R}^{2}$ value $(0.9396)$ was maximum as compared to First order, peppas, hixon crowell, higuchi model of VF5 formulation. Hence statistically it can be postulating that VF5 could be the best formulation with good diffusion-controlled released system (fig. 6 and table 12).

\section{Stability study}

The accelerated stability study of VF5; an optimized formulation was carried out as per ICH Q1A guideline at $40{ }^{\circ} \mathrm{C} \pm 2{ }^{\circ} \mathrm{C} / 75 \% \mathrm{RH} \pm 5 \% \mathrm{RH}$ for 6 mo using EZT-570S touch screen stability controller. Various physical parameters like hardness, friability, floating time, percentage drug content, \%CDR at $12^{\text {th }}$ hour was measured. After 6-month stability study VF5 formulations shows no significant changes in instability. However, floating time and \% cumulative drug release was significantly increasing during stability study, it may be due to the slight deformation of API during stability study (table 13) To know more about actual interaction or changes during 6 mo of stability study, two-way ANOVA was implicated. It shows interaction account for $0.12 \%$ of total variables. The $\mathrm{F}$ value was 16.30 , the degree of freedom number was 4 . The P-value was $<0$. 0001. As per two-way ANOVA the interaction was considered extremely significant and interaction was statistically significant.

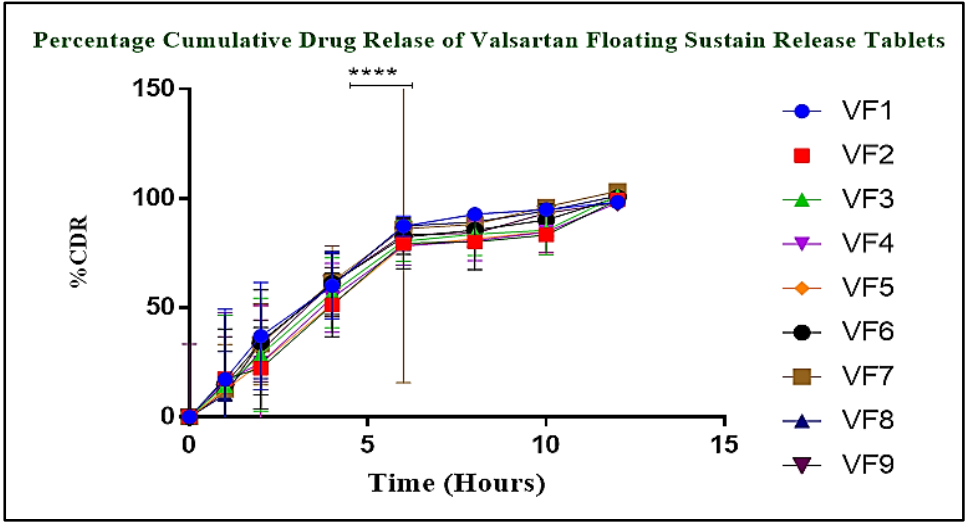

Fig. 1: \% CDR profile of valsartan floating tablets (VF1-VF9 batches) at $95.00 \%$ CI of differences and at mean \pm SD $(n=3) ;{ }^{* * * *}$ indicates high statistically significance $(\mathbf{p}<0.005)$

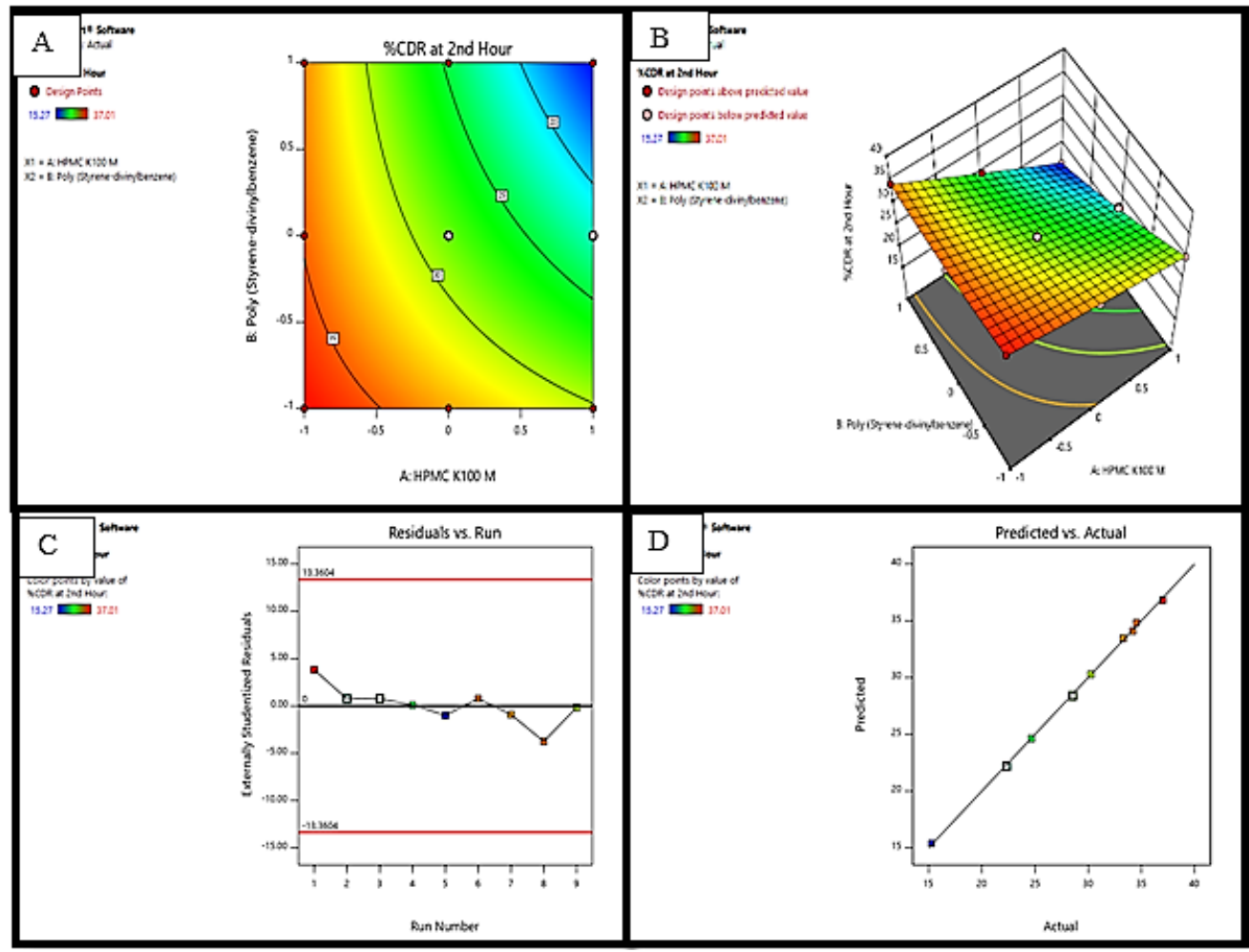

Fig. 2: Design expert output [A-counter, B-3D surface plot, C-residual vs run plot D-actual vs predicted plot] of effect of polymers concentration on $\%$ CDR at $2^{\text {nd }} h$ 


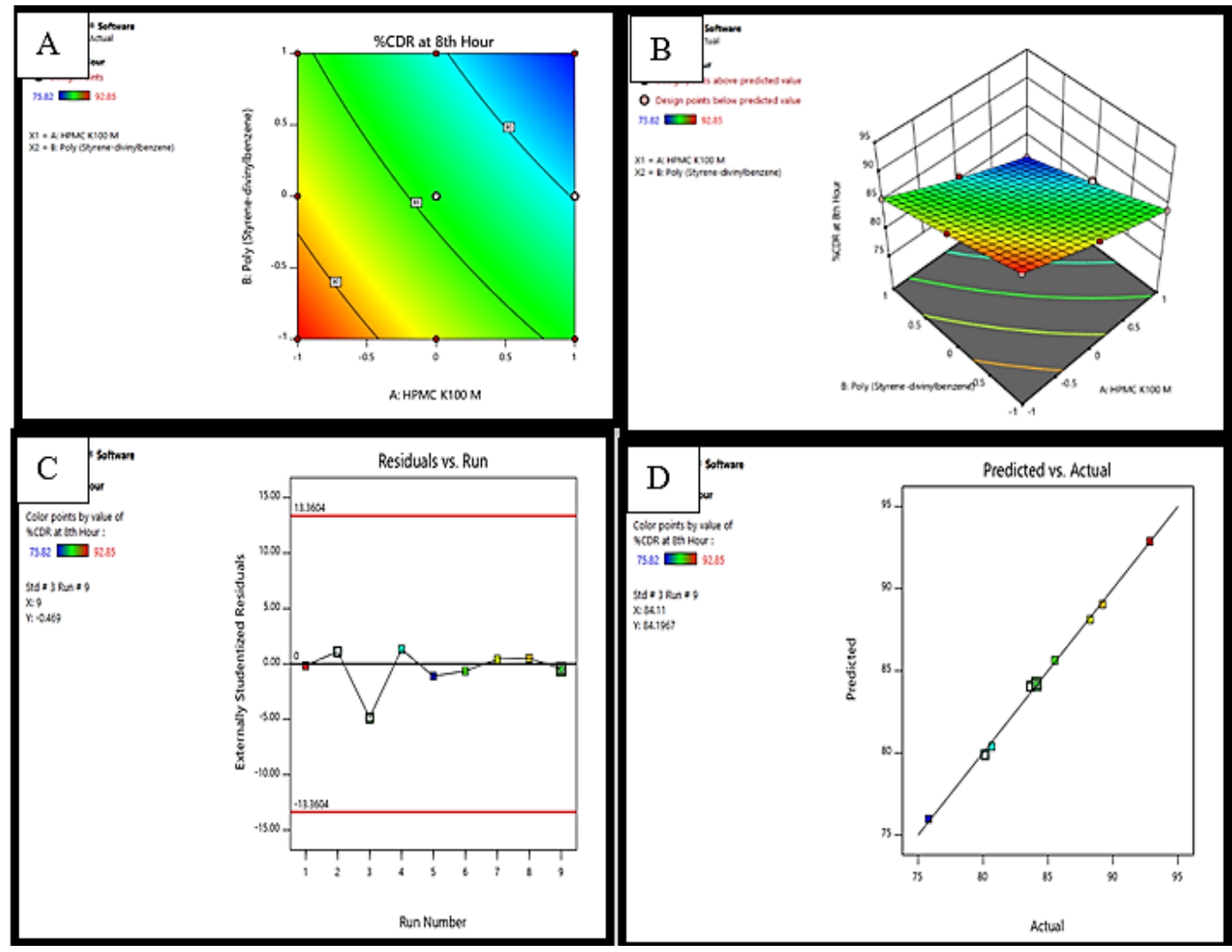

Fig. 3: Design expert output [A-counter, B-3D surface plot, C-residual vs run Plot D-actual vs predicted plot] of effect of polymers concentration on $\%$ CDR at $8^{\text {th }} h$

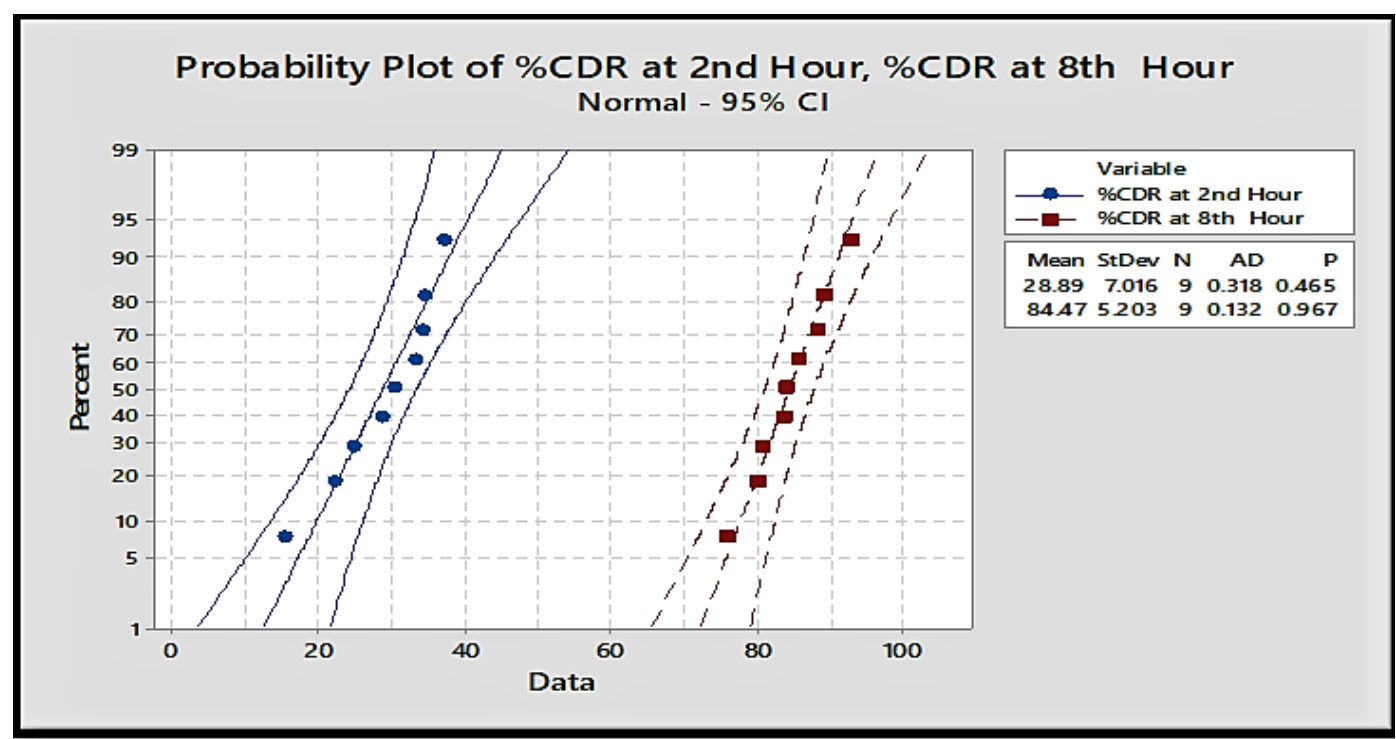

Fig. 4: Comparative probability plot of $\%$ CDR at 2 nd and $8^{\text {th }} h$

Table 1: Selection of variables levels for independent variables

\begin{tabular}{llll}
\hline (Independent variables) & & \\
\hline Levels & Coded value & Concentration of HPMC K100M in mg ( $\left.\mathbf{X}_{\mathbf{1}}\right)$ & $\begin{array}{l}\text { Concentration of poly (Styrene-divinylbenzene) } \\
\text { in } \mathbf{~ m g}\left(\mathbf{X}_{2}\right)\end{array}$ \\
\hline Low & & 40 & 20 \\
Intermediate & -1 & 50 & 30 \\
High & 0 & 60 & 40 \\
\hline
\end{tabular}




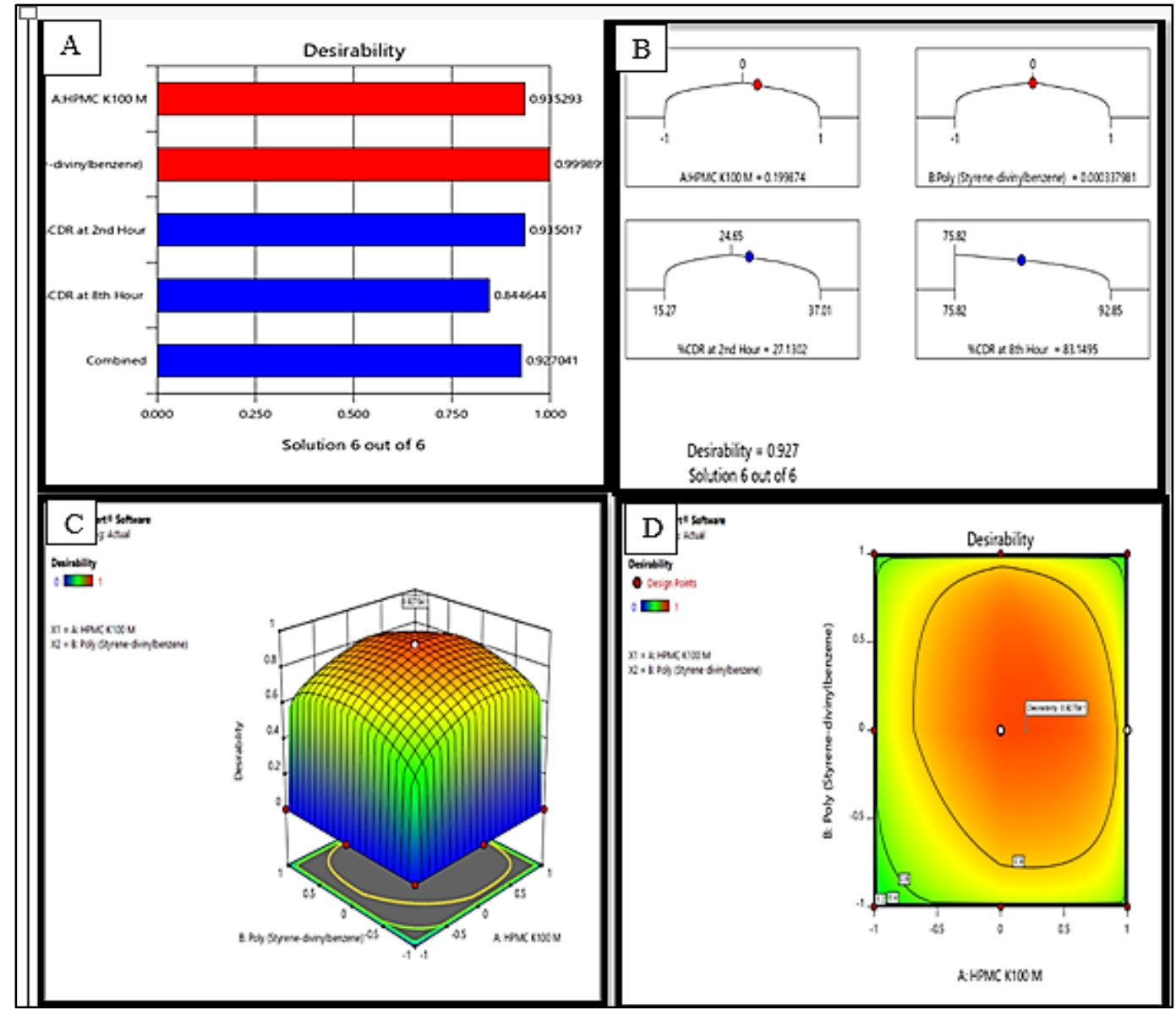

Fig. 5: Desirability function [A-bar chart, B-ramps chart, C-3D surface plot chart, D-counter plot]

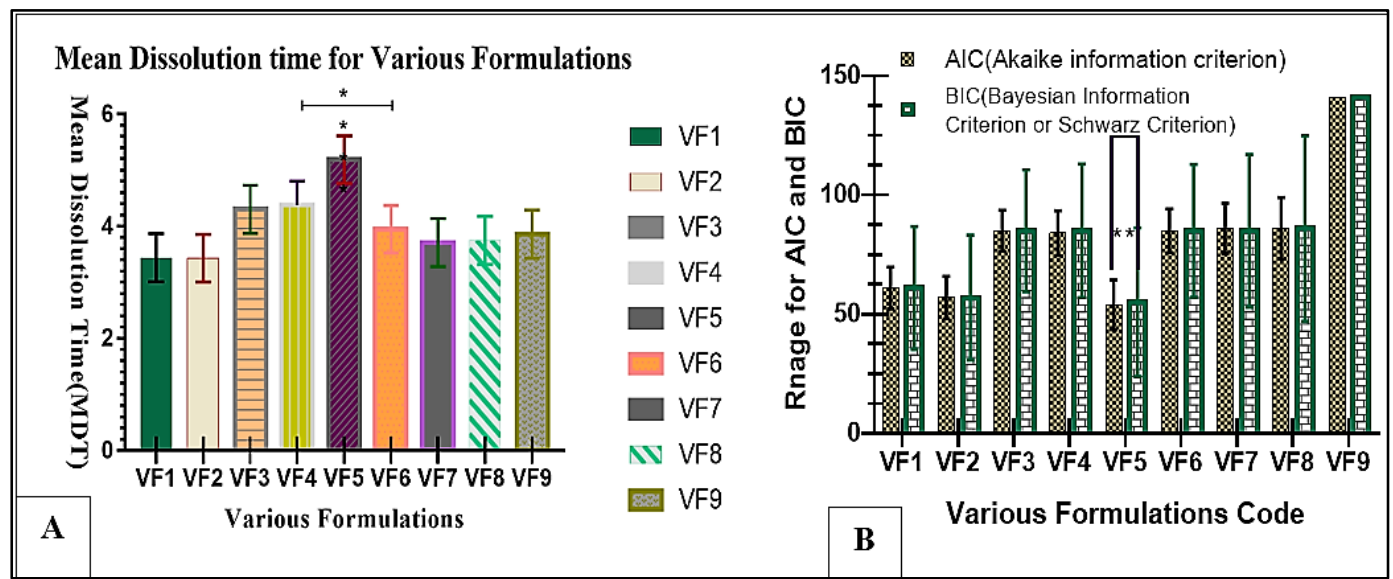

Fig. 6: [A]. Comparative mean dissolution study for VF1 to VF9 formulation at 95.00\%, CI of differences, and at mean \pm SD (n=3) [B]. A comparative profile of AIC and BIC values are represented as mean \pm SD $(n=3)$ on various valsartan floating formulations AIC and BIC at $\mathbf{9 5 . 0 0 \%} \mathrm{CI}$ of differences, $* *$ indicates high statistically significance $(\mathrm{p}<0.005)$

Table 2: Composition of factorial design batch

\begin{tabular}{|c|c|c|c|c|c|c|c|c|c|}
\hline Ingredients (mg) & VF1 & VF2 & VF3 & VF4 & VF5 & VF6 & VF7 & VF8 & VF9 \\
\hline Valsartan & 160 & 160 & 160 & 160 & 160 & 160 & 160 & 160 & 160 \\
\hline HPMC K100 M & 40 & 50 & 60 & 40 & 50 & 60 & 40 & 50 & 60 \\
\hline Poly (styrene-divinylbenzene) & 20 & 20 & 20 & 30 & 30 & 30 & 40 & 40 & 40 \\
\hline DCP & 55 & 45 & 35 & 45 & 35 & 25 & 35 & 25 & 15 \\
\hline Sodium bi carbonate & 20 & 20 & 20 & 20 & 20 & 20 & 20 & 20 & 20 \\
\hline Magnesium stearate & 3 & 3 & 3 & 3 & 3 & 3 & 3 & 3 & 3 \\
\hline Talc & 2 & 2 & 2 & 2 & 2 & 2 & 2 & 2 & 2 \\
\hline
\end{tabular}


Table 3: Pre compression parameters for all the factorial batches

\begin{tabular}{lllllll}
\hline $\begin{array}{l}\text { Batch } \\
\text { number }\end{array}$ & $\begin{array}{l}\text { Angle of } \\
\text { repose }\left({ }^{\circ}\right)\end{array}$ & $\begin{array}{l}\text { Bulk density } \\
(\mathbf{g} / \mathbf{m l})\end{array}$ & $\begin{array}{l}\text { Tapped } \\
\text { density }(\mathbf{g} / \mathbf{m l})\end{array}$ & $\begin{array}{l}\text { Carr's compressibility } \\
\text { index } \mathbf{( \% )}\end{array}$ & $\begin{array}{l}\text { Hausner } \\
\text { ratio }\end{array}$ & $\begin{array}{l}\text { Total porosity } \\
(\%)\end{array}$ \\
\hline VF1 & $32.87 \pm 0.012$ & $0.234 \pm 0.128$ & $0.263 \pm 0.129$ & $11.02 \pm 0.013$ & $\begin{array}{l}\text { Drug content } \\
(\%)\end{array}$ \\
VF2 & $33.28 \pm 0.023$ & $0.220 \pm 0.023$ & $0.254 \pm 0.023$ & $13.38 \pm 0.121$ & $1.12 \pm 0.014$ \\
VF3 & $35.18 \pm 0.123$ & $0.230 \pm 0.213$ & $0.267 \pm 0.271$ & $13.85 \pm 0.025$ & $1.15 \pm 0.123$ \\
VF4 & $34.29 \pm 0.283$ & $0.241 \pm 0.128$ & $0.277 \pm 0.361$ & $12.99 \pm 0.013$ & $13.38 \pm 0.023$ \\
VF5 & $37.29 \pm 0.281$ & $0.217 \pm 0.278$ & $0.250 \pm 0.273$ & $13.20 \pm 0.028$ & $93.17 \pm 0.034$ \\
VF6 & $31.28 \pm 0.023$ & $0.234 \pm 0.023$ & $0.263 \pm 0.172$ & $12.35 \pm 0.312$ & $1.14 \pm 0.022$ \\
VF7 & $29.38 \pm 0.381$ & $0.245 \pm 0.112$ & $0.267 \pm 0.281$ & $8.239 \pm 0.024$ & $12.99 \pm 0.313$ \\
VF8 & $33.56 \pm 0.824$ & $0.223 \pm 0.238$ & $0.288 \pm 0.271$ & $19.09 \pm 0.012$ & $97.19 \pm 0.015$ \\
VF9 & $38.39 \pm 0.213$ & $0.234 \pm 0.123$ & $0.254 \pm 0.234$ & $7.967 \pm 0.023$ & $13.20 \pm 0.122$ \\
\hline
\end{tabular}

All results were shown in mean \pm SD $(n=3)$

Table 4: List of variable importance for precompression parameters

\begin{tabular}{|c|c|c|c|}
\hline Pre compression variables & Variable number & Power & Importance \\
\hline Total porosity (\%) & 7 & 0.996230 & 1 \\
\hline Hausner ratio & 6 & 0.991326 & 2 \\
\hline Carr's compressibility index (\%) & 5 & 0.965853 & 3 \\
\hline Tapped density(g/ml) & 4 & 0.916766 & 4 \\
\hline Bulk density (g/ml) & 3 & 0.905470 & 5 \\
\hline Drug content $(\%)$ & 8 & 0.754903 & 6 \\
\hline Angle of repose $\left({ }^{\circ}\right)$ & 2 & 0.535868 & 7 \\
\hline
\end{tabular}

Table 5: Post compression parameters for all the formulations

\begin{tabular}{|c|c|c|c|c|c|c|c|c|}
\hline $\begin{array}{l}\text { Batch } \\
\text { number }\end{array}$ & $\begin{array}{l}\text { Average } \\
\text { weight (mg) }\end{array}$ & $\begin{array}{l}\text { Weight variation } \\
\text { test }(\%)\end{array}$ & $\begin{array}{l}\text { Drug content } \\
(\%)\end{array}$ & $\begin{array}{l}\text { Hardness } \\
\left(\mathrm{kg} / \mathrm{cm}^{2}\right)\end{array}$ & $\begin{array}{l}\text { Thickness } \\
\text { (mm) }\end{array}$ & $\begin{array}{l}\text { Friability } \\
(\%)\end{array}$ & $\begin{array}{l}\text { Floating } \\
\text { Time (sec) } \\
\end{array}$ & $\begin{array}{l}\text { In vitro buoyancy } \\
\text { study (h) }\end{array}$ \\
\hline VF1 & 300.51 & \pm 0.050 (Pass) & $92.34 \pm 0.45$ & $5.6 \pm 0.02$ & $5.4 \pm 0.18$ & $0.412 \pm 0.28$ & $116 \pm 0.37$ & 14 \\
\hline VF2 & 298.23 & \pm 0.809 (Pass) & $96.23 \pm 0.36$ & $5.2 \pm 0.06$ & $5.2 \pm 0.27$ & $0.429 \pm 1.61$ & $123 \pm 0.14$ & 15 \\
\hline VF3 & 302.21 & \pm 0.514 (Pass) & $97.38 \pm 0.11$ & $5.7 \pm 0.13$ & $5.6 \pm 0.37$ & $0.491 \pm 0.82$ & $136 \pm 0.02$ & 18 \\
\hline VF4 & 301.20 & \pm 0.178 (Pass) & $96.68 \pm 0.87$ & $5.2 \pm 0.22$ & $5.5 \pm 0.33$ & $0.512 \pm 1.27$ & $127 \pm 0.22$ & $>24$ \\
\hline VF5 & 302.17 & \pm 0.005 (Pass) & $98.11 \pm 0.38$ & $4.8 \pm 0.51$ & $5.7 \pm 0.38$ & $0.613 \pm 0.22$ & $132 \pm 0.33$ & 18 \\
\hline VF6 & 300.47 & $\pm 0.064($ Pass $)$ & $99.13 \pm 1.45$ & $5.2 \pm 0.02$ & $5.1 \pm 0.15$ & $0.531 \pm 0.38$ & $123 \pm 0.16$ & $>24$ \\
\hline VF7 & 301.63 & \pm 0.321 (Pass) & $96.19 \pm 0.41$ & $5.9 \pm 0.22$ & $5.8 \pm 1.82$ & $0.556 \pm 0.08$ & $117 \pm 0.05$ & 17 \\
\hline VF8 & 300.28 & \pm 0.127 (Pass) & $98.29 \pm 0.62$ & $6.4 \pm 0.27$ & $5.4 \pm 0.22$ & $0.536 \pm 0.28$ & $125 \pm 0.18$ & 16 \\
\hline VF9 & 299.27 & \pm 0.463 (Pass) & $96.31 \pm 0.42$ & $5.7 \pm 0.28$ & $5.3 \pm 0.02$ & $0.572 \pm 0.31$ & $130 \pm 0.37$ & $>24$ \\
\hline
\end{tabular}

All results were shown in mean \pm SD $(n=3)$

Table 6: variables importance for post compression parameters

\begin{tabular}{lll}
\hline Post compression variables & Variable number & Power \\
\hline Thickness (mm) & 4 & 0.923526 \\
Average weight (mg) & 1 & 0.832101 \\
Drug content (\%) & 3 & 0.776889 \\
Friability (\%) & 2 & 0.693686 \\
Floating time $(\mathrm{see})$ & 5 & 0.620322 \\
Hardness $\left(\mathrm{kg} / \mathrm{cm}^{2}\right)$ & 6 & 0.172067 \\
\hline
\end{tabular}

Table 7: Level of significance of $R 2$ value

\begin{tabular}{llll}
\hline Std. Dev. & 0.2560 & $\mathbf{R}^{\mathbf{2}}$ & 0.9995 \\
\hline Mean & 28.89 & Adjusted R & 0.9987 \\
C. V. \% & 0.8858 & Predicted R & 0.9944 \\
& & Adeq Precision & 102.6078 \\
\hline
\end{tabular}

Table 8: ANOVA for quadratic model on \%CDR at 2nd h

\begin{tabular}{|c|c|c|c|c|c|}
\hline Source & Sum of squares & df & Mean square & F-value & p-value \\
\hline Model & 393.65 & 5 & 78.73 & 1201.78 & significant \\
\hline $\mathrm{X}_{1}$-HPMC K100 M & 239.40 & 1 & 239.40 & 3654.37 & $<0.0001$ \\
\hline $\mathrm{X}_{2}$-poly (styrene divinylbenzene) & 116.42 & 1 & 116.42 & 1777.17 & $<0.0001$ \\
\hline $\mathrm{X}_{1} \mathrm{X}_{2}$ & 36.97 & 1 & 36.97 & 564.28 & 0.0002 \\
\hline $\mathrm{X}_{1}^{2}$ & 0.0242 & 1 & 0.0242 & 0.3694 & 0.5863 \\
\hline $\mathrm{X}_{2}^{2}$ & 0.8321 & 1 & 0.8321 & 12.70 & 0.0377 \\
\hline Residual & 0.1965 & 3 & 0.0655 & & \\
\hline Core Total & 393.85 & 8 & & & \\
\hline
\end{tabular}


Table 9: Fit statistics for $\%$ CDR at $8^{\text {th }} \mathbf{h}$

\begin{tabular}{llll}
\hline Std. Dev. & $\mathbf{0 . 3 6 0 8}$ & $\mathbf{R}^{\mathbf{2}}$ & $\mathbf{0 . 9 9 8 2}$ \\
\hline Mean & 84.47 & Adjusted R & 0.9952 \\
C. V. \% & 0.4271 & Predicted R & 0.9859 \\
& & Adeq Precision & 57.3382 \\
\hline
\end{tabular}

Table 10: ANOVA for quadratic model at $2^{\text {nd }} h$ of $\% C D R$

\begin{tabular}{|c|c|c|c|c|c|c|}
\hline Source & Sum of square & Df & Mean square & F-value & P-value & \\
\hline Model & 216.17 & 5 & 43.23 & 332.16 & 0.0003 & significant \\
\hline A-HPMC K100 M & 125.95 & 1 & 125.95 & 967.69 & $<0.0001$ & \\
\hline B-poly (styrene-divinylbenzene) & 89.55 & 1 & 89.55 & 688.04 & 0.0001 & \\
\hline $\mathrm{AB}$ & 0.2304 & 1 & 0.2304 & 1.77 & 0.2755 & \\
\hline$A^{2}$ & 0.3444 & 1 & 0.3444 & 2.65 & 0.2023 & \\
\hline $\mathrm{B}^{2}$ & 0.0882 & 1 & 0.0882 & 0.6777 & 0.4707 & \\
\hline Residual & 0.3905 & 3 & 0.1302 & & & \\
\hline Cor Total & 216.56 & 8 & & & & \\
\hline
\end{tabular}

Table 11: Checkpoint batch and standard error:

\begin{tabular}{llllll}
\hline & Actual & & Predicted & & Standard error \\
\hline Checkpoint Batch & \%CDR at $2^{\text {nd }}$ & \%CDR at $8^{\text {th }}$ & \%CDR at 2nd & \%CDR at 8 & for \%CDR at 2 \\
& Hour & Hour & Hour & Hour & Hour \\
VF10 & 29.67 & 87.48 & 28.39 & 84.05 & 4.31 \\
VF11 & 30.29 & 85.28 & 28.39 & 84.05 & 6.27 \\
VF12 & 29.36 & 86.67 & 28.39 & 84.05 & 3.92 \\
\hline
\end{tabular}

Table 12: Comparative kinetic model for VF1 to VF9 batches

\begin{tabular}{|c|c|c|c|c|c|c|c|c|c|}
\hline Statistical analytical criteria & VF1 & VF2 & VF3 & VF4 & VF5 & VF6 & VF7 & VF8 & VF9 \\
\hline Zero & 0.8726 & 0.918 & 0.911 & 0.9162 & 0.9396 & 0.8949 & 0.878 & 0.85948 & 0.8899 \\
\hline First & 0.9841 & 0.7801 & 0.8465 & 0.8809 & 0.7307 & 0.8994 & 0.9657 & 0.9529 & 0.9604 \\
\hline Peppas & 0.8099 & 0.8253 & 0.8308 & 0.8256 & 0.8683 & 0.82 & 0.8357 & 0.8452 & 0.8427 \\
\hline Hixon Crowell & 0.8573 & 0.8904 & 0.8831 & 0.8857 & 0.9198 & 0.8675 & 0.8767 & 0.8732 & 0.8765 \\
\hline Higuchi & 0.9586 & 0.9523 & 0.961 & 0.961 & 0.9328 & 0.9669 & 0.9598 & 0.9502 & 0.9532 \\
\hline AIC (Akaike Information Criterion) & 61.555 & 57.27 & 85.324 & 84.905 & 54.97 & 85.803 & 86.35 & 86.37 & 141.62 \\
\hline $\begin{array}{l}\text { BIC (Bayesian Information Criterion or } \\
\text { Schwarz Criterion) }\end{array}$ & 61.714 & $\begin{array}{l}5.74 \mathrm{E}+ \\
01\end{array}$ & 85.483 & 85.064 & 55.13 & 85.961 & 85.51 & 86.53 & 141.78 \\
\hline K1 & 0.34 & 0.332 & 0 & 0.28 & 0.324 & 0 & 0 & 0 & 0.313 \\
\hline RMSE (Root Mean Squared Error) & 12.9037 & 98.73 & 56.99 & 55.527 & 8.55 & 58.731 & 60.802 & 60.877 & 1923.25 \\
\hline $\begin{array}{l}\text { Percentage Dissolution Efficiency } \\
\text { (DE) }(\%)\end{array}$ & 70.1512 & 70.15 & 64.19 & 62.23 & 56.39 & 67.104 & 69 & 68.705 & 66.58 \\
\hline Mean Dissolution Time (MDT)(hr) & 3.439 & 3.431 & 4.3056 & 4.377 & 5.19 & 3.947 & 3.71 & 3.75 & 3.861 \\
\hline
\end{tabular}

Table 13: Accelerated stability study of VF5 formulation batch as per ICH Q1A guideline

\begin{tabular}{|c|c|c|c|c|c|}
\hline Duration & Hardness $\left(\mathrm{Kg} / \mathrm{cm}^{2}\right)$ & Friability (\%) & Floating time (See) & \%Drug content & $\%$ CDR at $12^{\text {th }}$ hours \\
\hline Initial & $4.8 \pm 0.43$ & $0.613 \pm 0.22$ & $132 \pm 0.33$ & $98.11 \pm 0.38$ & $99.38 \pm 0.51$ \\
\hline $1^{\text {st }}$ month & $4.4 \pm 1.51$ & $0.602 \pm 0.51$ & $133 \pm 0.45$ & $98.10 \pm 0.11$ & $100.23 \pm 0.67$ \\
\hline $2^{\text {nd }}$ month & $4.1 \pm 0.23$ & $0.588 \pm 0.71$ & $134 \pm 0.13$ & $97.76 \pm 0.30$ & $101.34 \pm 1.51$ \\
\hline $3^{\text {rd }}$ month & $3.8 \pm 0.32$ & $0.561 \pm 0.29$ & $137 \pm 0.18$ & $97.51 \pm 0.34$ & $102.45 \pm 1.34$ \\
\hline $4^{\text {th }}$ month & $3.7 \pm 0.41$ & $0.551 \pm 0.31$ & $139 \pm 0.43$ & $97.21 \pm 0.58$ & $104.24 \pm 1.05$ \\
\hline $5^{\text {th }}$ month & $3.6 \pm 0.46$ & $0.543 \pm 0.72$ & $141 \pm 0.11$ & $96.13 \pm 0.18$ & $104.34 \pm 1.22$ \\
\hline $6^{\text {th }}$ month & $3.5 \pm 0.27$ & $0.531 \pm 0.11$ & $144 \pm 0.34$ & $95.11 \pm 0.22$ & $105.35 \pm 2.14$ \\
\hline
\end{tabular}

All results were shown in mean \pm SD $(n=3)$

Table 14: Two-way ANOVA results for stability study for VF5 formulation batch as per ICH Q1A guideline

\begin{tabular}{lllll}
\hline Source of variation & \% of total variation & P value & P value summary & Significant? \\
\hline Interaction & 0.1167 & $<0.0001$ & $* * * *$ & Yes \\
Row factor & 0.02947 & $<0.0001$ & $* * * *$ & Yes \\
Column factor & 99.79 & $<0.0001$ & $* * * *$ & Yes \\
ANOVA table & SS & DF & MS & F (DFn, DFd) \\
Interaction & 885.8 & 24 & 36.91 & $\mathrm{~F}(24,210)=16.3$ \\
Row factor & 223.7 & 6 & 37.29 & $\mathrm{~F}(6,210)=16.47$ \\
Column Factor & 757655 & 4 & 189414 & $\mathrm{~F}(4,210)=83649$ \\
Residual & 475.5 & 210 & 2.264 & $\mathrm{P}<0.0001$ \\
\hline
\end{tabular}

$* * * *$ indicates a higher level of significance 


\section{DISCUSSION}

The main intention of this research was to evaluate valsartan floating tablets using various statistical approach. To prepare 160 mg valsartan to contain floating tablets, 40-60 mg of HPMC K100 M and 20-40 mg of poly (styrene-divinylbenzene) were used as principal polymers as shown in table 2 . From the precompression parameters of all the nine factorial batches shown in table 3 , it was confirmed that all the formulation bland has fair to good angle of repose $\left(29.38 \pm 0.381\right.$ to $\left.38.39 \pm 0.213^{\circ}\right)$, excellent bulk density $(0.217 \pm 0.278$ to $0.245 \pm 0.112 \mathrm{~g} / \mathrm{ml})$, excellent tapped density $(0.250 \pm 0.273$ to $0.288 \pm 0.271 \mathrm{~g} / \mathrm{ml})$, good percentage carr's compressibility index $(7.967 \pm 0.023$ to $19.09 \pm 0.012 \%)$, moderate hausner ratio $(1.08 \pm 0.044$ to $1.16 \pm 0.014)$, good percentage porosity $(7.874 \pm 0.912$ to $22.56 \pm 0.091 \%)$ and adequate percentage drug content $(92.12 \pm 0.056$ to $98.18 \pm 0.912 \%)$. From the variable importance studies performed in Statistica 12 software on post compression parameters mentioned in table 4 , it was confirmed that, among the pre-compression parameters, total porosity (\%) has highest variable importance, hence total porosity (\%) could influence valsartan floating tablet efficacy. In a similar pattern, from post-compression parameters, all the batches reported to have very good tablet average weight (298.23 to $302.21 \mathrm{mg}$ ), limited percentage weight variation, excellent percentage drug content $(92.34 \pm 0.45$ to $99.13 \pm 1.45 \%)$, adequate hardness $(4.8 \pm 0.51$ to $\left.6.4 \pm 0.27 \mathrm{~kg} / \mathrm{cm}^{2}\right)$, moderate thickness $(5.1 \pm 0.15$ to $5.8 \pm 1.82 \mathrm{~mm})$, limited percentage friability $(0.412 \pm 0.28$ to $0.613 \pm 0.22 \%)$ and effective floating time ( $116 \pm 0.37$ to $136 \pm 0.02$ see). From the statistical variable importance study performed in Statistica 12 software (table 6) on post-compression parameters, it was confirmed that tablet thickness has higher influence on floating tablets of valsartan. From the comparative kinetic model studies shown in table 12 on all the nine batches, it was proposed that VF5 happened to be the optimized formulation because it follows best zero-order kinetics (R2=0.9396), minimum AIC value (54.97) and minimum BIC (55.13) value as compared with the rest of the formulations. Nevertheless, VF5 reported to have marginal RMSE value (8.55) and least Percentage Dissolution Efficacy (PDE) (56.39\%) and higher Mean Dissolution Time (MDT) (5.19hr) as compared to other formulations. Further, by performing desirability study it was confirmed that VF5 was found to be the best-optimized batch. The optimized VF5 formulation was observed in accelerated stability condition as per ICH Q1A guideline; and found to have very stable after six-month stability studies.

\section{CONCLUSION}

Valsartan floating drug delivery system was developed by considering HPMC K100M and poly (styrene-divinylbenzene) as principal polymers. Total nine formulations were prepared (VF1VF9) and optimized by Response Surface Mythology (RSM) based Box-Bentham design. The main intention of this research was to evaluate valsartan floating tablets using various statistical approach. After all the evaluation studies VF5 formulations was emerges as an optimized formulation. From the six-month stability study results of VF5 formulations, it was also reviled that the VF5 formulation; encompassing $50 \mathrm{mg}$ of HPMC K100M and $30 \mathrm{mg}$ poly (styrenedivinylbenzene) shows no significant changes in physical and chemical characteristics after six months accelerated conditions (40 $\left.{ }^{\circ} \mathrm{C} \pm 2{ }^{\circ} \mathrm{C} / 75 \% \mathrm{RH} \pm 5 \% \mathrm{RH}\right)$. Thus, from the above conclusion, it was summarized that valsartan floating tablets were successfully prepared but in vivo bouncy study and in vivo pharmacokinetics in an animal model is warrant to established proper in vitro and in vivo correlation.

\section{RESEARCH INVOLVING HUMAN AND/OR ANIMAL RIGHTS}

The author did not perform any study with human or animal subjects.

\section{ACKNOWLEDGEMENT}

Author is like to acknowledge the cordial support during experimental proceedings, extending from Department of Pharmaceutical Engineering and Technology IIT (BHU), Varanasi

\section{AUTHOR CONTRIBUTION}

All the work have been carried out by me

\section{CONFLICT OF INTERESTS}

Author did not receive any conflict of interest. The author is solely responsible for the conduct of experiments and writing of this article.

\section{REFERENCES}

1. Iborra Egea O, Galvez Monton C, Roura S, Perea Gil I, Prat Vidal $\mathrm{C}$, Soler Botija C, et al. Mechanisms of action of sacubitril/valsartan on cardiac remodeling: a systems biology approach. NPJ Syst Biol Appl 2017;3:12.

2. Ansara AJ, Kolanczyk DM, Koehler JM. Neprilysin inhibition with sacubitril/valsartan in the treatment of heart failure: mortality bang for your buck. J Clin Pharm Ther 2016;41:119-27.

3. Verdecchia P, Angeli F. Assessment of the optimal daily dose of valsartan in patients with hypertension, heart failure, or both. Clin Thera 2004;26:460-72.

4. Kshirsagar SJ, Patil SV, Bhalekar MR. Statistical optimization of floating pulsatile drug delivery system for chronotherapy of hypertension. Int J Pharm Invest 2011;1:207-13.

5. Sokar M, Hanafy A, Elkamel A, El-Gamal S. Design of chronomodulated drug delivery system of valsartan: in vitro characterization. Indian J Pharm Sci 2015;77:470-7.

6. Mandal UK, Chatterjee B, Senjoti FG. Gastro-retentive drug delivery systems and their in vivo success: a recent update. Asian J Pharm Sci 2016;11:575-84.

7. Marini A, Berbenni V, Moioli S, Bruni G, Cofrancesco P, Margheritis C, et al. Drug-excipient compatibility studies by Physico-chemical techniques: the case of Indomethacin. J Therm Anal Calorim 2003;73:529-45.

8. Vemula S, Venisetty RK, Veerareddy P. Valsartan floating bioadhesive compression-coated mini-tablets: formulation and pharmacokinetics; 2017.

9. Ahmed MS, Afaf AR, Amal SmAE-e, Yasmin IMM. Formulation and optimization of itraconazole proteasomes using box behnken design. Int J Appl Pharm 2018;10:41.

10. Anas TA, Ali Khidher A. Formulation and in vitro evaluation of amlodipine gastro retentive floating tablets using a combination of hydrophilic and hydrophobic polymers. Int J Appl Pharm 2018;10:126-34.

11. Gharti KP, Thapa P, Budhathoki U, Bhargava A. Formulation and in vitro evaluation of floating tablets of hydroxypropyl methylcellulose and polyethylene oxide using ranitidine hydrochloride as a model drug. J Young Pharm JYP 2012;4:201-8.

12. Senjoti FG, Mahmood S, Jaffri JM, Mandal UK. Design and in vitro evaluation of sustained-release floating tablets of metformin $\mathrm{HCl}$ based on effervescence and swelling. Iranian J Pharm Res 2016;15:53-70.

13. Malana MA, Zohra R. The release behavior and kinetic evaluation of tramadol $\mathrm{HCl}$ from chemically cross-linked ter polymeric hydrogels. DARU J Pharm Sci 2013;21:10.

14. Brewer MJ, Butler A, Cooksley SL. The relative performance of AIC, AICC and BIC in the presence of unobserved heterogeneity. Methods Ecol Evolution 2016;7:679-92.

15. Bose A, Wong TW, Singh N. Formulation development and optimization of sustained release matrix tablet of Itopride $\mathrm{HCl}$ by response surface methodology and its evaluation of release kinetics. Saudi Pharm J 2013;21:201-13. 